Article

\title{
Perceived Quality of Urban Wetland Parks: A Second-Order Factor Structure Equation Modeling
}

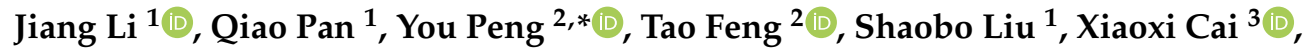 \\ Chixing Zhong ${ }^{3,4}$, Yicheng Yin ${ }^{5}$ and Wenbo Lai ${ }^{6}$ \\ 1 School of Architecture and Art, Central South University, Changsha 410083, China; lijiang@csu.edu.cn (J.L.); \\ panqiao@csu.edu.cn (Q.P.); liushaobo@csu.edu.cn (S.L.) \\ 2 Urban Planning and Transportation Group, Department of the Built Environment, Eindhoven University of \\ Technology, De Groene Loper 6, PO Box 513, 5600MB Eindhoven, The Netherlands; t.feng@tue.nl \\ 3 College of Art and Design, Hunan First Normal University, Changsha 410205, China; \\ xiaoxi@hnu.edu.cn (X.C.); zhongchixing@yeah.net (C.Z.) \\ 4 School of Architecture, Hunan University, Changsha 410082, China \\ 5 Institute of Geographic Sciences and Natural Resources Research, Chinese Academy of Sciences, \\ Beijing 100101, China; yinyicheng1983@163.com \\ 6 School of Architecture, South China University of Technology, Guangzhou 510641, China; laiwb@scut.edu.cn \\ * Correspondence: y.peng@tue.nl
}

Received: 18 August 2020; Accepted: 31 August 2020; Published: 3 September 2020

check for updates

\begin{abstract}
Wetland in the urban or peri-urban areas has been recognized as an important component of urban ecosystems and provides ecological and environmental services. Wetland park emerged as a kind of restoration of natural wetlands in the context of increasing pressure on land and eco-environment caused by urban sprawl, which has played an essential role in providing recreational spaces/opportunities and improving social interactions. However, little research has been conducted on the theoretical formulation elaborating individuals' perceived quality of wetland parks when people are engaging in activities therein. This study is an attempt to develop a method to measure the quality of wetland parks based on individuals' various perceptions and attitudes. From the view of human-nature interaction, the perceived quality is hypothetically conceptualized as a composite of two dimensions, such as comfort perception and environmental satisfaction. A series of questionnaire-based surveys were conducted among respondents $(\mathrm{N}=936)$ in Yanghu wetland park in Changsha, China. Based on the measured items from on-site surveys, second-order factor structural equation modeling is applied to estimate the hypothesis of a hierarchical structure for elaborating how the quality of wetland park is perceived by individual respondents. The results test the hypothesis that the quality of wetland park as a second-order theoretical construct can be conceptualized by two first-order theoretical constructs, individuals' comfort (loading $=0.749$ ), and environmental satisfaction (loading $=0.828$ ). In addition, a significant influence of attitudes toward green space on the perceived quality of wetland park has been identified.
\end{abstract}

Keywords: urban wetland park; perceived quality; outdoor comfort; attitude toward green space; environmental satisfaction; second-order factor structural equation modeling

\section{Introduction}

Rapid urbanization is expected to emerge in developing countries in the next several decades, reflected in the number of urban inhabitants exceeding $60 \%$ of the world's population by the year 2030 [1]. The rise of population density and urban sprawl is expected to cause a dramatic increase in buildings and paved impermeable surfaces. As increasing stress is placed upon urban nature and the ecosystem, the reduction of green covers and degradation of water bodies eventually will raise 
the heat island phenomenon and anthropogenic energy consumptions in urban areas [2,3]. Meanwhile, multiple problems and threats for urban areas are likely to happen due to climate change, such as heat stress, extreme precipitation, inland and coastal flooding, landslides, air pollution, drought, and water scarcity [4]. The provision of a comfortable open space in urban environments has become a major challenge in people's quality of life.

Urban nature has been widely recognized as an important part of urban infrastructure providing a variety of ecosystem functionalities and services, contributing to sustainable urban development [5]. Findings of empirical investigations have indicated that the presence of natural areas and green infrastructures in cities has the potential to fend off the adverse challenges on vulnerable urban environments and positively affects the life quality of inhabitants [6-11]. Consequently, investigations on people's comfort perception related to urban nature and green infrastructure grows steadily [12-15]. It is well documented that exposure in green space is associated with numerous health benefits [16-21].

Urban wetland park, known as an ecological infrastructures and an important component of urban green space system, benefits the residents in reducing the damage caused by floods, replenishing water supplies, improving water and air quality, cooling the atmosphere, and promoting human comfort and wellbeing [22-25]. However, driven by anthropogenic pressures, wetlands have rapidly dwindled and replaced by constructed living spaces and excavated water holding facilities for runoff capture [26]. Due to a process of continuous deterioration caused by urban growth, the wetlands adjacent to urban or peri-urban areas may never return to their natural statuses. In the context of environmental perturbation, a paradigm of wetland rehabilitation is supposed to shift and prioritize the functions and values for providing ecological benefits and urban open-space amenities [27-29]. The conservation policies for wetlands should be not only feasible but also socially acceptable [30]. Besides the ecological value [31,32], a great potential in the use of green space is emphasized, as the wetland park provides opportunities for physical activities, enjoyment of nature, and social interaction for inhabitants and visitors [33]. The importance of human-nature interaction for individual psycho-physiological restoration from daily stress through the exposure to green space in wetland parks is acknowledged for enhancing wellbeing [34,35].

Although the benefits of urban green space are well known, strong incentives are still needed for improving the quality of urban wetland parks, referring to participants' attitude toward urban green space, environmental satisfaction, and comfort perception. Attitudes toward urban green space, which can be represented by manifest items through questionnaire-based surveys, implies people's preference and need in green and natural environments. Human comfort and environmental satisfaction are key indicators in assessing the quality of environments [36]. To assess the quality of wetland parks from the participants' perspective, we need to improve our knowledge on how people experience and perceive the environments [37]. It has been evidenced that various physical attributes and management of green spaces are associated with people's comfort, environmental perception, and satisfaction $[14,38]$. This study delves into this rather complex issue by theoretically exploring the hierarchical structure regarding the relationships between perceived quality and the latent theoretical constructs in terms of attitude toward urban green space, environmental satisfaction, and comfort perception. We aim to broaden the understanding of the individual's various perceptions in a wetland environment and gain new insights into the quality of wetland parks in different dimensions. The study on wetland park quality may offer significant steps towards changing the wetland park to be more livable and encourage inhabitants spend more time doing outdoor activities in green space.

\section{Conceptual Framework}

There are many theoretical constructs which can be meaningfully conceptualized at a higher-order of abstraction [39]. As a joint product of various features of the environment interacting with individuals' relevant psychological process, the appreciation of quality is directly associated with meeting people's needs and making people comfortable. In the context of human-nature interaction, the quality of a wetland park can be conceptualized as a composite of two dimensions such as people's comfort 
perception and environmental satisfaction, which are presumed at the first-order level of abstraction inferred from measured variables. Meanwhile, the perceived quality of a wetland park is influenced by the first-order theoretical construct of attitude toward green space. The second-order model is posited to estimate the relationships between the first-order latent variables and measured variables, and the second-order latent variables and the first-order variables. A second-order factor structural equation modeling would be the most feasible approach which can represent such a hierarchical structure, that implies the association between a second-order factor and the measured variables (manifest items surveyed) is mediated by the first-order factors.

The proposed conceptual framework is depicted in Figure 1. It orients the studies on human-nature interaction in urban wetland parks, which serves ultimately the purpose to build the concepts of attitude, comfort, and satisfaction regarding wetland environment as three first-order theoretical constructs, represented by latent variables. Variables in rectangles denoted by $I_{a}, I_{c}$, and $I_{s}$ are vectors of measured variables of theoretical constructs. Subsequently, evaluations of the first-order latent variables are aggregated to form the second-order construct of perceived quality of wetland parks.

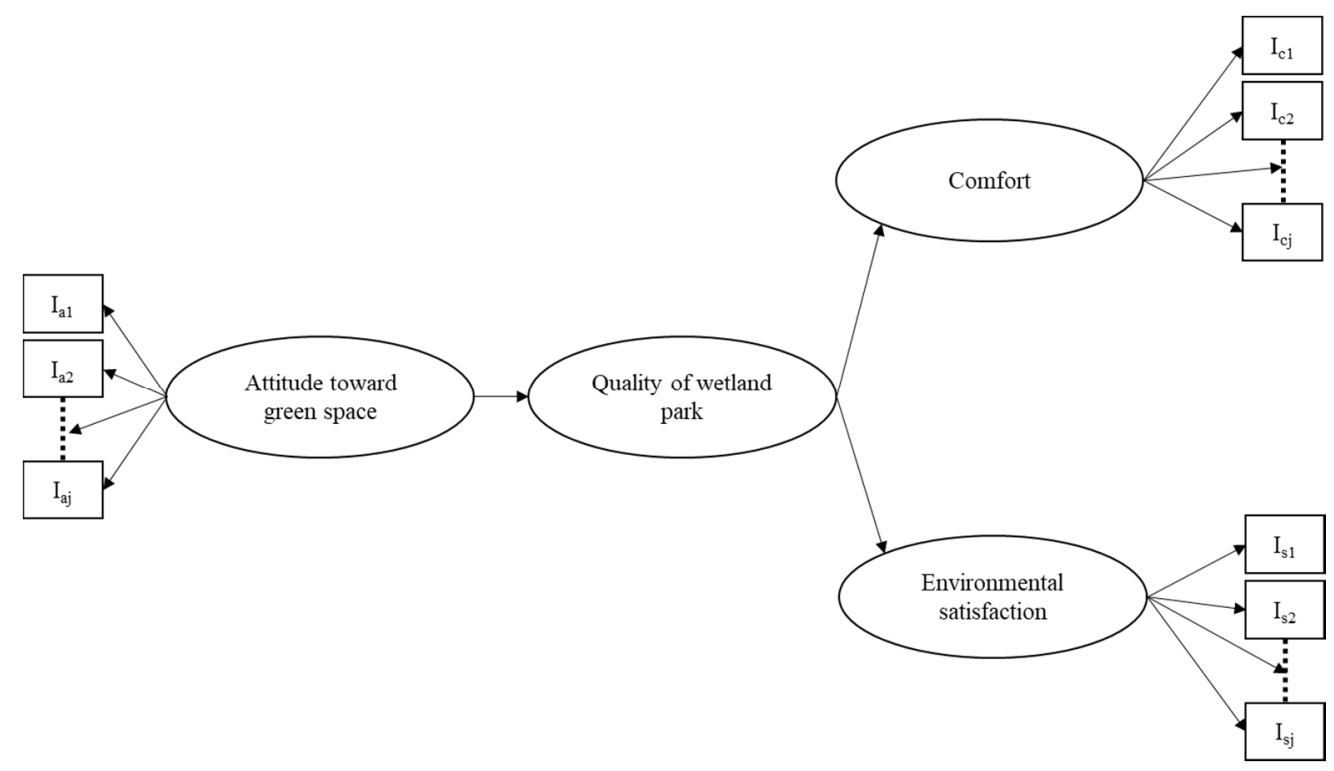

Figure 1. The conceptual framework.

As a complex multi-dimensional construct, attitude toward green space is influenced by an individuals' personal characteristics and the context $[40,41]$. However, measuring individual attitudes toward urban green spaces has received scarce coverage in the environment and planning literature [42]. Attitude is not directly measurable, therefore inferred indicators are commonly used to construct the attitude measurements through manifest items in questionnaire surveys [40]. Likert items with agree or disagree options are usually applied to operationalize the attitude construct. The challenge of measuring people's attitude is how to select representative items.

Environmental satisfaction involves the subjective evaluation on the features and settings of a given environment, which indicates how much the given environment meets the needs of people [36]. As a general construct, environmental satisfaction in our conceptual framework is represented by the subjective evaluations regarding various environmental features of wetland parks, including noise, air quality, aesthetics, diversity of plants, facilities, barrier-free settings, number of trees, hygiene and insect conditions.

Human comfort is the integrated perception based on various microclimatic variables and environmental stimuli that is related to individuals' socio-demographics, behavioral, and psychological factors [43-46]. The scope of comfort has been broadened from just physiological sensation to a cognitive activity where individuals make a holistic judgment based on the surrounding environment. 
Individuals participate in activities in wetland parks with their own purposes and expectations and are able to adapt to the changed environment to some extent. On the other hand, an individual's adaptation can be promoted or delimited by opportunities and constraints of wetland parks in terms of physical and social contexts. Comfort is constructed as a latent variable indicated by multiple indicators, such as thermal sensation and perceptions of wind velocity, solar radiation and humidity.

It is important to realize that individuals' preferences, expectations, and perceptions with respect to various features are related to the quality of wetland parks. Environmental factors constraining one person might facilitate another person and vice versa. Theoretical construct of quality of a wetland park represents the integrated evaluation on subjective perceptions of wetland parks in this conceptual framework. Here, the quality of wetland parks is treated as a latent variable of interest, which is conceptualized by the theoretical construct of comfort and satisfaction represented also as latent variables. Natural experiences are linked to the improved comfort perception $[6,7,47,48]$. However, to assess the quality of wetland parks, it is not sufficient to describe only whether the environment is comfortable or not, it is more important to understand people's attitude and satisfaction related to the various features of wetland parks.

\section{Methodology}

\subsection{Study Area}

Yanghu wetland park is located in the southwest of Changsha (see Figure 2), a large city with a population more than 3 million in the central south of China [49]. Changsha is the capital and most populous city of Hunan province. The city has a humid subtropical climate (Cfa) [50], featuring warm spring, hot summer, cool autumn and cold winter. In recent years, the urban area has been rapidly sprawling towards its periphery.

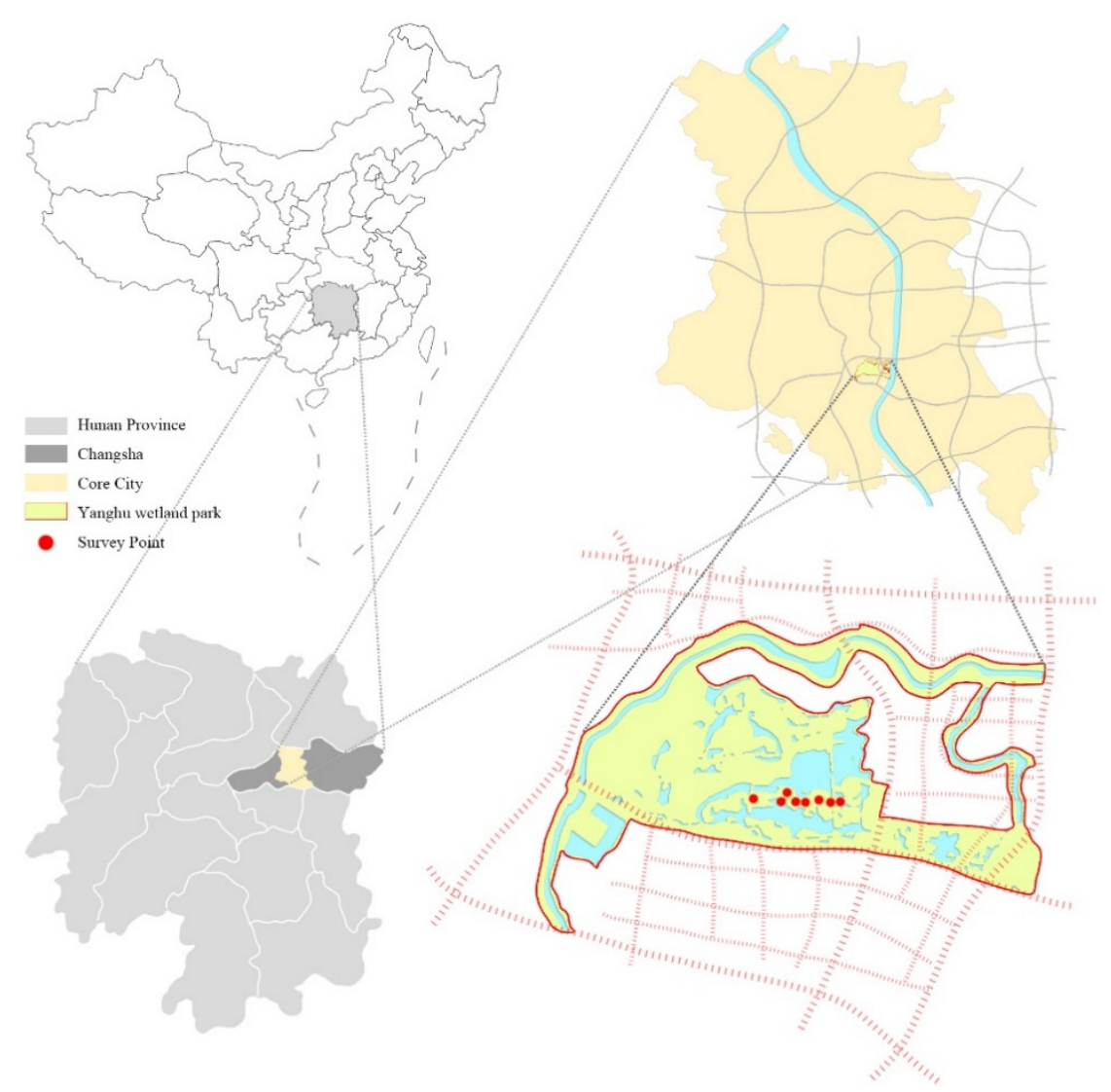

Figure 2. Location of Yanghu wetland park in Changsha, Hunan Province, China. 
As they have experienced unprecedented economic growth, cities in China experienced sharp air pollution and environmental deterioration, which increases inhabitants' awareness and demand of protection for urban green amenities and better access to natural landscapes [51]. From the perspective of lending direct supports to people' quality of life, the restoration of wetlands in urban and peri-urban areas provides open spaces for physical, recreational, and social activities for residents and improves local microclimate and counteracts the negative environmental stimuli [52]. In recent years, nationwide developments of urban wetland parks have been launched in many cities in China, as a part of the sponge city programs for urban water management in order to manage stormwater and hydrological systems, in the context of urbanization and the urban water crisis [53]. In this context, Yanghu wetland park was established based on a natural river wetland and an artificial wetlands in 2010, which is bordered by Jin River on the south and east, south Xiaoxiang Avenue on the west and Yanghu Avenue on the north, covering an area of 478.7 hectares [54].

Yanghu wetland park is nourished by surface runoff waters, precipitation, and underground waters. The wetland areas in the park cover 170.3 hectares, which consists of natural river wetlands and artificial wetlands. The proportion of wetland areas coverage in the entire park and the ratio of different types of wetlands are shown in Figure 3. The pool areas in the park covers 116 hectares and the river in the park covers 53.4 hectares. Besides the water areas, green space covers 281.3 hectares. The studied plots are distributed in the central park area nearby the waterfront, where artificial interventions were exerted to facilitate the participation of walking, rest, leisure, social and physical activity. The scenes of different studied spots are shown in Figure 4.

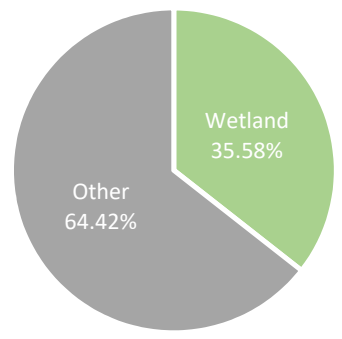

(a)

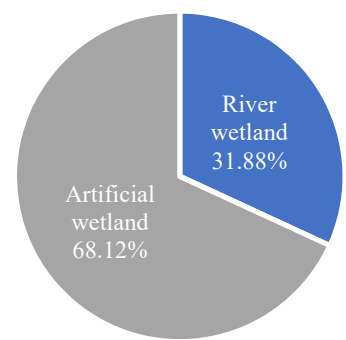

(b)

Figure 3. (a) proportion of wetland cover; (b) proportion of river wetland and artificial wetland.
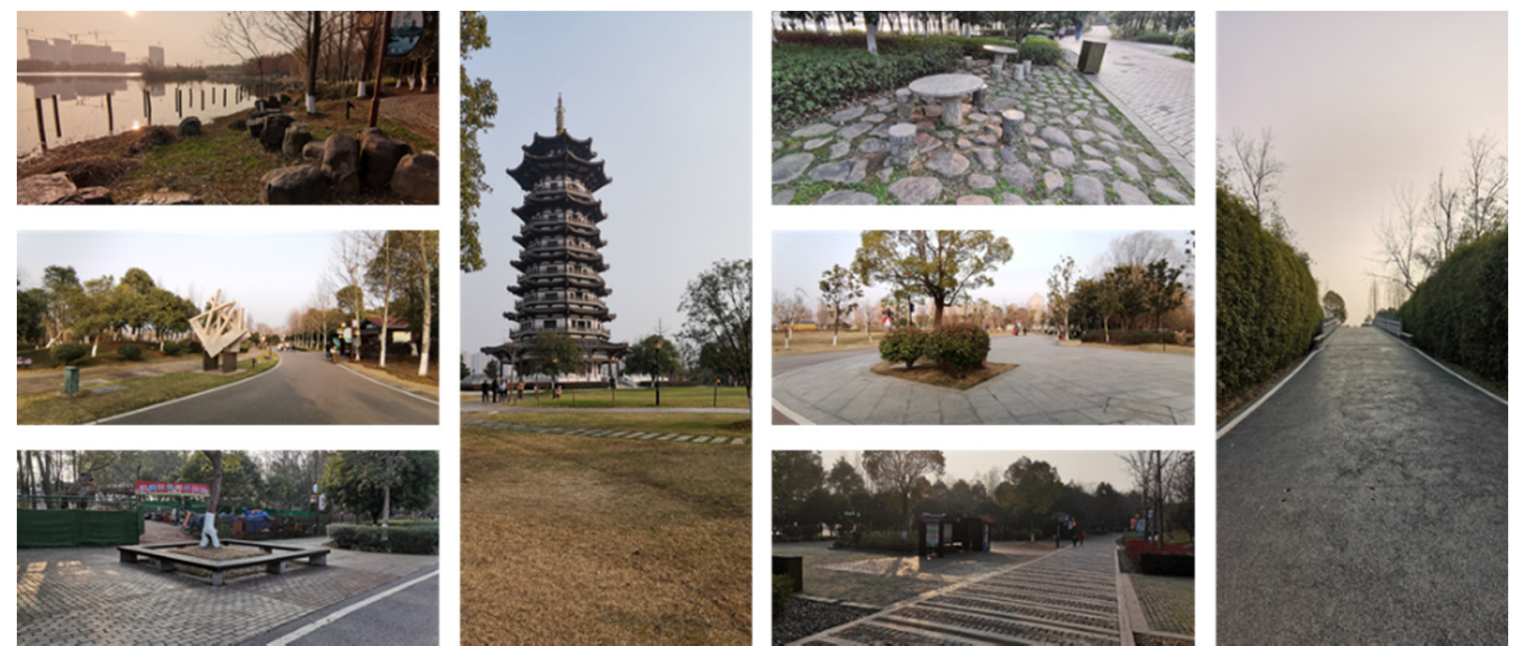

Figure 4. The scenes of studied plots in Yanghu wetland park.

\subsection{Questionnaire and Survey}

For the purpose of this study, a three-part questionnaire was developed. The first part of the questionnaire includes questions about respondent's demographical characteristics, socio-economic 
status, dwelling conditions, transportation modes and time, and behavioral factors related to the visit of wetland parks. The second part of the questionnaire collects information of respondents' attitudes toward urban green spaces. The identically constructed attitudinal questions were asked, with responses given using a five-point Likert scale with anchor ends of strongly disagree and strongly agree. The last part of the questionnaire focuses on the respondent's perceptions of microclimate and evaluations of various features of wetland parks, which pertains to participants' comfort and satisfaction. For the perceptions of microclimate and environmental features, questions are posed with responses of seven-point scales. The questionnaire form applied in surveys are in Chinese. According to the privacy rules, no trackable personal information was obtained.

The survey was carried out in Yanghu urban wetland park with the assistance of university students. Before the field work, students were trained in the procedures and etiquette of conducting surveys. From 19th October to 24th November 2019, a team of student research assistants started randomly inviting the participants in sampled plots to join in the questionnaire interviews. At the beginning of each survey, it required a research assistant to introduce and explain the survey purpose to the participants. On average, the survey takes about $10 \mathrm{~min}$ to complete. In the end, the survey successfully interviewed thousands of respondents face-to-face and obtained 936 effective samples for further studies.

\subsection{Second-Order Factor Structural Equation Modeling}

Structural equation modeling (SEM) is a general statistical modeling method widely used in social and behavioral sciences to test and evaluate multivariate causal relationships, which can be viewed as a combination of factor analysis and regression or path analysis [55-57]. SEM differs from other modeling methods since it estimates the direct and indirect effects on hypothetical causal relationships. Unlike the regression model with a single equation that has a single dependent variable and multiple explanatory variates, SEM has a number of equations with several explanatory variables in each of them. The dependent variables in one equation of SEM might be an independent variable in another equation.

The variables in SEM are classified as endogenous and exogenous variables. Exogenous variables can only be independent variables, but endogenous variable can appear as an independent variable in one equation and an independent variable in another equation. The variables in SEM are also divided as latent and measured variables. Latent variables are factors that are important to the model which we cannot obtain from dataset, while measured variables are collected and saved in dataset [58].

The SEM is segmented into two parts, the measurement model and the structural model. The measurement model specifies the relationship between latent construct and its manifest items, while the structural model specifies the relationships between latent constructs. The second-order SEM is posited, which inherently consists of a measurement model that specifies the relationship between the manifest items and their respective first-order latent variables, and the first-order latent variables related to the second-order latent variable(s), and a structural model that delineates links between latent variables. The second-order model recognizes the contribution and retains the idiosyncratic nature of each first-order construct, and treats such constructs as facets of the second-order construct [39]. The coefficients of the relationship between first-order construct and its second-order construct and thus the statistical contribution of each first-order construct can be estimated. The quality of a wetland park is conceptualized as a second-order composite of first-order theoretical constructs such as individuals' comfort and environmental satisfaction. The SEM also specifies the influence of first-order latent variable of attitude toward green space on perceived quality of wetland parks.

Once model identification has been established, the model estimates then proceeds. Statistically, the SEM is estimated by comparing two variance-covariance matrices. If the closest estimate of the implied variance-covariance matrix with vector $\Theta$ of model parameters $(\Sigma(\Theta))$ to the estimated population variance-covariance matrix $(S)$ is found, the model is fit to the data. Regarding the function 
$F[S, \Sigma(\Theta)]$, the most commonly used minimization criterion is maximum likelihood (ML), which is expressed as:

$$
F_{M L}=\log |\Sigma(\Theta)|+\operatorname{trace}\left\{S \Sigma^{-1}(\Theta)\right\}-\log |S|-(p+q)
$$

where $p$ is the number of measured variables and $q$ denotes the sample size. The derivation of ML estimator assumes that all measured variables come from a multinormal distribution.

To examine the fit of a hypothesized model, various goodness-of-fit indexes are used in this study. The comparative fit index (CFI) [59] provides a measure of complete covariance in the data, which ranges from 0 to 1 . A higher CFI value indicates a better fit. As evidence of adequate fit, the value of CFI should be equal or greater than 0.90 . The root mean squared error of approximation (RMSEA) [60] is a measure of the estimated discrepancy between the population and model-implied population covariance matrices per degree of freedom. RMSEA is an index where 0 indicates the perfect fit and higher values means a lack of fit. If the value of RMSEA is equal or less than 0.06 , the model is adequate fit. The standardized root mean square residual (SRMR) [60] is a measure of the average of standardized fitted residuals. A value smaller than 0.08 indicates a good fit.

\section{Results and Discussion}

\subsection{Descriptive Statistic Results}

According to the results of descriptive statistical analysis (Table 1), varieties are found among samples according to the demographic characteristics, socio-economic status, and dwelling conditions. Males account for $46 \%$ of the respondents which is a little less than female respondents. Significant percentages of respondents are in the 16-30-year and 31-45-year age groups. More than half of the sampled population is married. Over two-thirds of the respondents received college degrees or higher education. More than half of the respondents are employed, and the other half involves students and other types of jobs (e.g., freelancer, entrepreneur, etc.). Regarding monthly income denominated by Chinese Yuan (CNY), 52.8\% of respondents earn less than $5000 \mathrm{CNY}$ including over one-third of respondents with no independent income. Compared with the per-capita monthly income in Changsha (about $4233 \mathrm{CNY}$ ) [61], income of more than 15,000 CNY is relatively high. According to the statistical results, respondents belonging to this income category only account for $4.8 \%$ of the entire sampled population. The overwhelming majority of respondents are residents, still, $5.3 \%$ of respondents are visitors from outside the city. The dwelling condition relates to the ownership and size of residences. Accordingly, residential ownerships are generally classified into "rent" and "purchased," which are split fifty-fifty. Respondents owning their house mostly live with a partner or other family members.

Table 1. Demographic characteristics, socio-economic status, and dwelling conditions.

\begin{tabular}{lll}
\hline Gender & Male & $46.0 \%$ \\
& Female & $54.0 \%$ \\
\hline Age & $\leq 15$ & $2.7 \%$ \\
& $16-30$ & $53.0 \%$ \\
& $31-45$ & $30.0 \%$ \\
& $46-60$ & $9.5 \%$ \\
& $>60$ & $4.8 \%$ \\
\hline Civil status & Married & $53.3 \%$ \\
& Unmarried & $43.4 \%$ \\
Education level & Divorced or widowed & $3.3 \%$ \\
\hline & High school and below & $28.1 \%$ \\
& Undergraduate & $61.9 \%$ \\
& Graduate & $10.0 \%$ \\
\hline
\end{tabular}


Table 1. Cont.

\begin{tabular}{lll}
\hline Employment & Student & $29.3 \%$ \\
& Jobless or unemployed & $7.1 \%$ \\
& Employed & $54.8 \%$ \\
& Other & $8.8 \%$ \\
\hline Income & $<5000 \mathrm{CNY}$ & $52.8 \%$ \\
& $5000-10000 \mathrm{CNY}$ & $27.5 \%$ \\
& $10000-15000 \mathrm{CNY}$ & $14.9 \%$ \\
& $>15,000 \mathrm{CNY}$ & $4.8 \%$ \\
\hline Local residential time & Non-local resident & $5.3 \%$ \\
& $<1$ year & $27.0 \%$ \\
& $1-5$ years & $29.4 \%$ \\
& $>5$ years & $38.3 \%$ \\
\hline Residential ownership & Joint tenancy & $34.9 \%$ \\
& Rent (alone) & $11.9 \%$ \\
& Purchased (alone) & $2.8 \%$ \\
& Purchased (with family) & $50.4 \%$ \\
\hline Residential size & $<90 \mathrm{~m}^{2}$ & $34.0 \%$ \\
& $90-120 \mathrm{~m}^{2}$ & $36.6 \%$ \\
& $120-150 \mathrm{~m}^{2}$ & $23.5 \%$ \\
& $>150 \mathrm{~m}^{2}$ & $5.9 \%$ \\
\hline
\end{tabular}

The transportation-related factors are important to outdoor experiences, which may further influence people's satisfaction and comfort with outdoor activities [44]. As shown in Table 2, only 6.3\% respondents visiting the Yanghu wetland park are living less than $500 \mathrm{~m}$ from the park. More than half respondents traveled more than $2.5 \mathrm{~km}$ for visiting the wetland park. Apparently, the wetland park attracts many local visitors who live in the neighborhood far away from the park. As for transportation modes, $17.8 \%$ respondents came to the park by foot and $8.5 \%$ respondents rode bikes to the park. The respondents who take public transportation accounts for $35.6 \%$ of the sample. The rest of the respondents used taxi, cars hailed online, or a private car. The time people spent on the road from dwelling to the park is mostly shorter than $45 \mathrm{~min}$.

Table 2. Proportion of population regarding transportation and behavioral factors.

\begin{tabular}{lll}
\hline Distance from residence & $<0.5 \mathrm{~km}$ & $6.3 \%$ \\
& $0.5-1.5 \mathrm{~km}$ & $16.6 \%$ \\
& $1.5-2.5 \mathrm{~km}$ & $23.7 \%$ \\
& $2.5-3.5 \mathrm{~km}$ & $20.8 \%$ \\
& $>3.5 \mathrm{~km}$ & $32.5 \%$ \\
\hline Transport mode & By foot & $17.8 \%$ \\
& By bike & $8.5 \%$ \\
& By taxi or online car hailing & $17.3 \%$ \\
& By bus or metro & $35.6 \%$ \\
& By private car & $17.8 \%$ \\
& Other & $3.0 \%$ \\
\hline Transport time & $<15$ min & $21.6 \%$ \\
& $15-30$ min & $40.0 \%$ \\
& $30-45$ min & $25.5 \%$ \\
& $45-60$ min & $10.1 \%$ \\
& $>60$ min & $2.8 \%$ \\
\hline
\end{tabular}

Based on the results shown in Table 3, the main purposes for visiting the wetland park are walking, resting, and social and recreational activities, which accounts for $44.8 \%, 17.6 \%$, and $24.5 \%$ respectively. Some $6.5 \%$ of respondents came to the park for physical activities and the other $6.6 \%$ respondents 
came for other purposes. Regarding the time spent on outdoor activities, most respondents spent less than $2 \mathrm{~h}$ in outdoor environments and less than $1 \mathrm{~h}$ in the wetland park. Some $14.6 \%$ respondents visited the wetland park for the first time, $38.8 \%$ respondents visited the wetland park a few times in a year, and $28.8 \%$ respondents came to the wetland park several times per month. More frequent visits have been taken by $9.8 \%$ respondents, who went to the park many times per week. Moreover, $8 \%$ respondents visit the park almost every day.

Table 3. Proportion of population regarding behavioral factors.

\begin{tabular}{lll}
\hline Purpose & Walking & $44.8 \%$ \\
& Resting & $17.6 \%$ \\
& Social activity and recreation & $24.5 \%$ \\
& Physical activity & $6.5 \%$ \\
& Other & $6.6 \%$ \\
\hline Total outdoor duration & $<30 \mathrm{~min}$ & $21.7 \%$ \\
& $30-60 \mathrm{~min}$ & $31.7 \%$ \\
& $60-90 \mathrm{~min}$ & $26.1 \%$ \\
& $90-120 \mathrm{~min}$ & $19.0 \%$ \\
& $>120 \mathrm{~min}$ & $1.5 \%$ \\
\hline Duration in studied plots & $<15$ min & $11.5 \%$ \\
& $15-30 \mathrm{~min}$ & $21.5 \%$ \\
& $30-45 \mathrm{~min}$ & $25.5 \%$ \\
& $45-60$ min & $15.5 \%$ \\
& $>60$ min & $26.0 \%$ \\
\hline Frequency of visit & First time & $14.6 \%$ \\
& A few times in a year & $38.8 \%$ \\
& A few times in a month & $28.8 \%$ \\
& Several time per week & $9.8 \%$ \\
& Almost every day & $8.0 \%$ \\
\hline
\end{tabular}

\subsection{Estimation Results of the Second-Order Factor SEM}

The significant test results of indexes for goodness-to-fit are shown in Table 4, which provides an evidence of a good fit model. The structure of estimated second-order factor SEM is depicted in Figure 5. The acronyms of exogenous variables are explained in Table 5. According to the results shown in Table 6, all measured variables have statistically significant relationships with their latent variables. Notice that the loadings of the first-order latent variables to the second-order latent variables exceed 0.70 that are substantive and statistically significant, which indicates the quality of the wetland park contributes to comfort (coefficient $=0.749, p$-value $=0.000$ ) and environmental satisfaction (coefficient $=0.828, p$-value $=0.000$ ). This points out a very strong relationships between perceived quality of the wetland park and comfort and environmental satisfaction, which attests to the convergent validity of theoretical construct of quality of wetland parks meaningfully conceptualized through second-order modeling. Based on the hypothetic conceptual framework, the structural model where quality of wetland park is specified as the dependent variable and the first-order latent variable, namely attitude toward green space, is presumed to affect the second-order factor. The result of the coefficient regarding this relationship is 0.560 , which attests to the effects of attitude toward green spaces on perceived quality of wetland parks is rather potent.

Table 4. Indexes for model goodness-to-fit.

\begin{tabular}{cccc}
\hline CFI & TLI & RMSEA & SRMR \\
\hline 0.913 & 0.900 & 0.064 & 0.047 \\
\hline
\end{tabular}




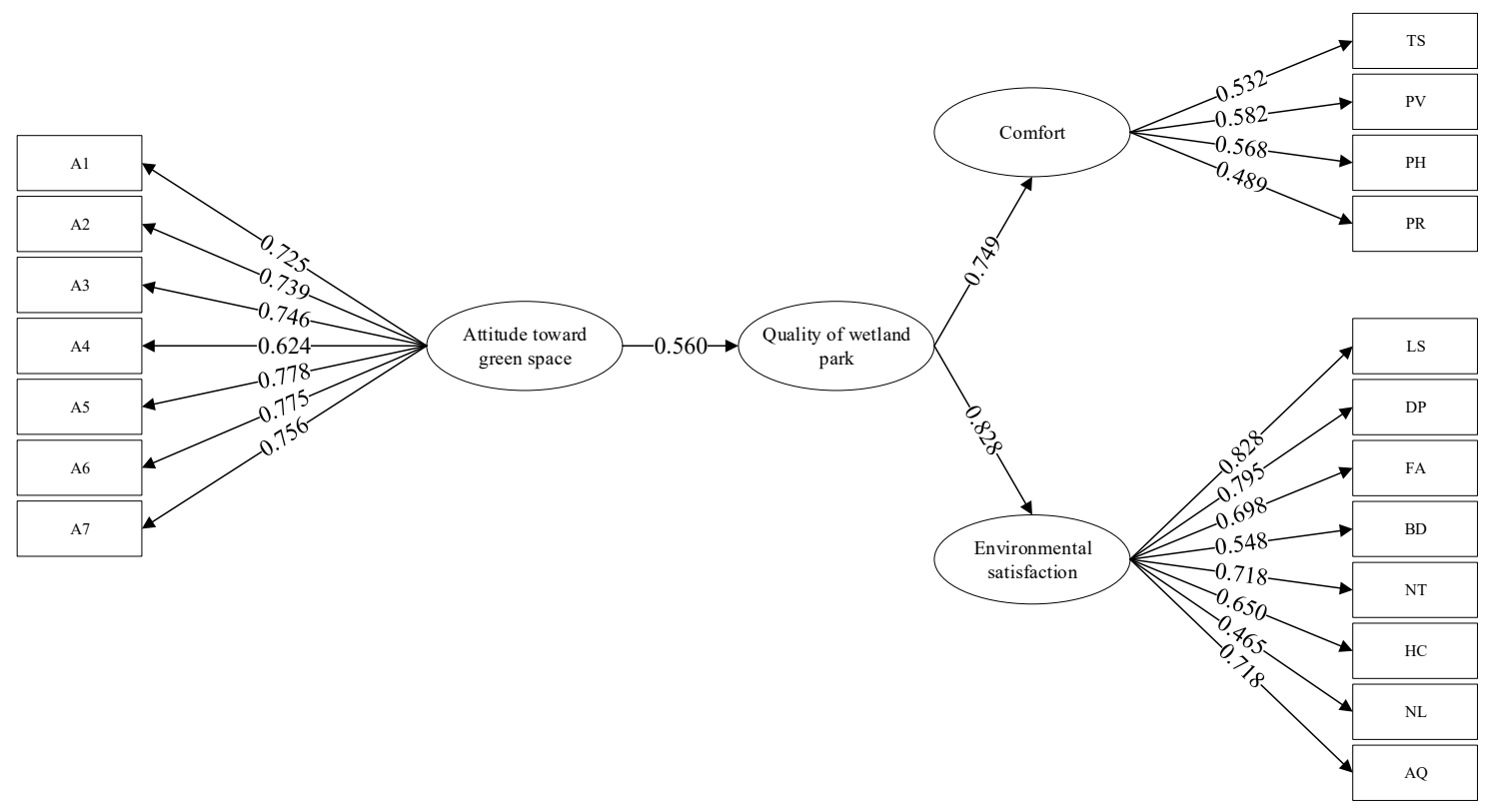

Figure 5. Diagram of second-order factor SEM.

Table 5. Nomenclature of manifest items.

\begin{tabular}{llll}
\hline TS & Thermal sensation & PH & Perceived humidity \\
PV & Perceived wind velocity & PR & Perceived solar radiation \\
LS & Landscape aesthetics & NT & Number of trees \\
DP & Diversity of plants & HC & Hygienic condition \\
FA & Facility & NL & Noise level \\
BD & Barrier-free design & AQ & Air quality \\
A1 & Experience in green space helps restoration & \\
A2 & Increasing the green space will contribute to urban sustainable development \\
A3 & Green spaces improve comfort and aesthetics of urban environments \\
A4 & I prefer outdoor activity especially in green spaces \\
A5 & City inhabitants should spend more time in open green spaces \\
A6 & More efforts should be made in green space cleaning and management \\
A7 & Plants in urban green spaces need stated maintenance \\
\hline
\end{tabular}

Table 6. Results of second-order factor SEM estimate.

\begin{tabular}{lccc}
\hline & & Estimate & $p$-Value \\
\hline Attitude toward green space & by & & \\
A1 & & 0.725 & 0.000 \\
A2 & 0.739 & 0.000 \\
A3 & 0.746 & 0.000 \\
A4 & 0.624 & 0.000 \\
A5 & 0.778 & 0.000 \\
A6 & 0.775 & 0.000 \\
A7 & 0.756 & 0.000 \\
\hline Comfort & by & & \\
TS & & 0.532 & 0.000 \\
PV & 0.582 & 0.000 \\
PH & 0.568 & 0.000 \\
PR & & 0.490 & 0.000 \\
\hline Environmental satisfaction & by & & \\
LS & & 0.828 & 0.000 \\
DP & & 0.795 & 0.000 \\
FA & & 0.698 & 0.000 \\
\hline
\end{tabular}


Table 6. Cont.

\begin{tabular}{|c|c|c|c|}
\hline & & Estimate & $p$-Value \\
\hline BD & & 0.548 & 0.000 \\
\hline NT & & 0.718 & 0.000 \\
\hline $\mathrm{HC}$ & & 0.650 & 0.000 \\
\hline NL & & 0.465 & 0.000 \\
\hline $\mathrm{AQ}$ & & 0.718 & 0.000 \\
\hline Quality of wetland park & by & & \\
\hline Comfort & & 0.749 & 0.000 \\
\hline Environmental satisfaction & & 0.828 & 0.000 \\
\hline Quality of wetland park & on & & \\
\hline Attitude toward green space & & 0.560 & 0.000 \\
\hline
\end{tabular}

To our knowledge, the loading of the relationship between comfort and specific perceived microclimatic impact is highly dependent on the contexts. The factor loadings regarding the comfort range from 0.490 to 0.582 . Although the difference of loadings for each measured variable is small, the perceived wind velocity has the strongest correlation with comfort among measured variables. We noticed that the green space in wetland park may reduce the wind velocity which gives people pleasant feeling thereby producing more comfort. As the field experiment was carried out in the end of autumn, the loading of association between thermal sensation and comfort is 0.532 , thus, the wetland's cooling effects probably loss its weight in comfort assessment.

The measured variables, including the evaluation of landscape aesthetic, diversity of plants, number of trees, and air quality, are highly correlated with environmental satisfaction, since their factor loadings exceed 0.7. The measured variables of facility, hygienic condition and barrier-free design concern amenities and management of wetland parks, which are associated with environmental satisfaction with a loading of $0.698,0.650$, and 0.550 , respectively. To some extent, the quality of wetland parks can be indirectly derived from the aspects related to the items with high weight of loading, which reflects that participants patronize and spend some time in the wetland park for encountering nature and experiencing the beauty of landscapes. The lowest loading of 0.465 is related to the association of perceived noise level and environmental satisfaction. One possible reason is that the noise disturbance has been lower in the environments of wetland parks compared with other circumstances in urban public spaces. Based on the data, the perceived environmental acoustic level is skewed towards quiet and stabilized. The manifest items involve questions on environmental benefits provided by urban green space, preference of outdoor activity in green spaces, and management of green space. The results show that the loadings for common variances of each manifest item in the form of questions explained by attitude toward green spaces are significantly large and most of them are higher than 0.7 .

\section{Conclusions}

This study focuses on developing a theoretical framework for evaluating the perceived quality of wetland parks in urban areas. Based on the data obtained from surveys in Yanghu wetland park, a set of variables forms a reliable instrument to conceptualize the first-order latent variables regarding attitudes toward green spaces, comfort, and environmental satisfaction of people. Thus, we hypothesized that the quality of wetland parks is a higher-order theoretical construct conceptualized by individuals' comfort and environmental satisfaction as having two dimensions and influenced by individuals' attitude toward urban green spaces. According to the estimation results of the proposed second-order factor SEM, the hypotheses of second-order hierarchical structure has been verified.

So far, there has been a rather limited amount of research concerning quality of wetland parks that addresses comprehensive analysis on latent constructs with various dimensions of respondents' psychological factors. To the best of our knowledge, the present study is the first to relate comfort and environmental satisfaction to the quality of wetland parks and emphasizes the role of human-nature 
interactions in assessing the quality of wetland parks. Perceived measures even without correspondent objective measurements are essential since perceptions are the basis for people's evaluation.

From the perspective of urban planning and management, the complexity of second-order construct indicates that improving quality of environment is beyond the efforts on physical settings, which should fully consider users' various needs and perceptions. The present work provides a step towards a user-centered approach to studying human-nature dynamic interactions and establishing interdisciplinary criterion for assessing the quality of environment. Although this study focuses on the perceived quality of Yanghu wetland park in Changsha, the conceptual framework and approaches of data collection and modeling are feasible to be generalized in other wetland parks in various forms in different regions and countries. Certainly, the calibrations on measured variables are required, depending on the local environmental and cultural contexts and residents' demographic and socio-economic characteristics. The perceptions may differ from person to person; however, the analysis in this study is limited to the average perceived quality of wetland parks of the entire sampled population. Further studies are expected to include the analysis on physical features of environment in wetland parks and the potential heterogeneity among visitors.

Author Contributions: Conceptualization, J.L., Q.P., Y.P., T.F., S.L. and X.C.; methodology, J.L., Q.P., Y.P. and T.F.; formal analysis, J.L., Q.P. and Y.P.; investigation, J.L., Q.P., X.C., S.L., C.Z. and Y.Y.; data curation, Q.P., C.Z. and Y.Y.; writing-original draft, J.L., Q.P. and Y.P.; writing- review \& editing, Y.P., T.F., S.L. and W.L.; supervision, S.L.; funding acquisition, J.L. and X.C. All authors have read and agreed to the published version of manuscript.

Funding: This research was funded by "National Natural Science Foundation of China, grant number 51909283", "Natural Science Foundation of Hunan Province, grant number 2018JJ3096" and "Humanities and Social Science Fund of Ministry of Education of China, grant number 20YJCZH003".

Acknowledgments: We thank all student assistants for their hard work. We appreciate the respondents for their cooperation and patients in surveys. We sincerely thank the reviewers and editors.

Conflicts of Interest: The authors declare no conflict of interest.

\section{References}

1. United Nations World Urbanization Prospects. 2018. Available online: https://population.un.org/wup/ Publications/Files/WUP2018-Report.pdf (accessed on 28 June 2020).

2. Grimmond, S. Urbanization and global environmental change: Local effects of urban warming. Geogr. J. 2007, 173, 83-88. [CrossRef]

3. Stewart, I.D.; Oke, T.R. Local climate zones for urban temperature studies. Bull. Am. Meteorol. Soc. 2012, 93, 1879-1900. [CrossRef]

4. Karakounos, I.; Dimoudi, A.; Zoras, S. The influence of bioclimatic urban redevelopment on outdoor thermal comfort. Energy Build. 2018, 158, 1266-1274. [CrossRef]

5. Chiesura, A. The role of urban parks for the sustainable city. Landsc. Urban Plan. 2004, 68, 129-138. [CrossRef]

6. Bowler, D.E.; Buyung-Ali, L.; Knight, T.M.; Pullin, A.S. Urban greening to cool towns and cities: A systematic review of the empirical evidence. Landsc. Urban Plan. 2010, 97, 147-155. [CrossRef]

7. Dimoudi, A.; Nikolopoulou, M. Vegetation in the Urban Environment: Microclimatic analysis and benefit. Energy Build. 2003, 35, 69-76. [CrossRef]

8. Ambrey, C.; Fleming, C. Public Greenspace and Life Satisfaction in Urban Australia. Urban Stud. 2014, 51, 1290-1321. [CrossRef]

9. Ambrey, C.L. An investigation into the synergistic wellbeing benefits of greenspace and physical activity: Moving beyond the mean. Urban For. Urban Green. 2016, 19, 7-12. [CrossRef]

10. Chen, Y.; Zheng, B.; Hu, Y. Numerical Simulation of Local Climate Zone Cooling Achieved through Modification of Trees, Albedo and Green Roofs-A Case Study of Changsha, China. Sustainability 2020, 12, 2752. [CrossRef]

11. Badach, J.; Dymnicka, M.; Baranowski, A. Urban Vegetation in Air Quality Management: A Review and Policy Framework. Sustainability 2020, 12, 1258. [CrossRef]

12. Coccolo, S.; Pearlmutter, D.; Kaempf, J.; Scartezzini, J.L. Thermal comfort maps to estimate the impact of urban greening on the outdoor human comfort. Urban For. Urban Green. 2018, 35, 91-105. [CrossRef] 
13. Cohen, P.; Potchter, O.; Matzarakis, A. Daily and seasonal climatic conditions of green urban open spaces in the Mediterranean climate and their impact on human comfort. Build. Environ. 2012, 51, 285-295. [CrossRef]

14. Klemm, W.; Heusinkveld, B.G.; Lenzholzer, S.; Jacobs, M.H.; Van Hove, B. Psychological and physical impact of urban green spaces on outdoor thermal comfort during summertime in The Netherlands. Build. Environ. 2015, 83, 120-128. [CrossRef]

15. Wang, Y.; de Groot, R.; Bakker, F.; Wörtche, H.; Leemans, R. Thermal comfort in urban green spaces: A survey on a Dutch university campus. Int. J. Biometeorol. 2017, 61, 87-101. [CrossRef] [PubMed]

16. Dadvand, P.; Bartoll, X.; Basagaña, X.; Dalmau-Bueno, A.; Martinez, D.; Ambros, A.; Cirach, M.; Triguero-Mas, M.; Gascon, M.; Borrell, C.; et al. Green spaces and General Health: Roles of mental health status, social support, and physical activity. Environ. Int. 2016, 91, 161-167. [CrossRef] [PubMed]

17. Twohig-Bennett, C.; Jones, A. The health benefits of the great outdoors: A systematic review and meta-analysis of greenspace exposure and health outcomes. Environ. Res. 2018, 166, 628-637. [CrossRef] [PubMed]

18. James, P.; Banay, R.F.; Hart, J.E.; Laden, F. A Review of the Health Benefits of Greenness. Curr. Epidemiol. Rep. 2015, 2, 131-142. [CrossRef]

19. Dadvand, P.; Nieuwenhuijsen, M.J.; Esnaola, M.; Forns, J.; Basagaña, X.; Alvarez-Pedrerol, M.; Rivas, I.; López-Vicente, M.; De Pascual, M.C.; Su, J.; et al. Green spaces and cognitive development in primary schoolchildren. Proc. Natl. Acad. Sci. USA 2015, 112, 7937-7942. [CrossRef]

20. Ekkel, E.D.; de Vries, S. Nearby green space and human health: Evaluating accessibility metrics. Landsc. Urban Plan. 2017, 157, 214-220. [CrossRef]

21. Liu, B.; Lian, Z.; Brown, R.D. Effect of Landscape Microclimates on Thermal Comfort and Physiological Wellbeing. Sustainability 2019, 11, 5387. [CrossRef]

22. Shashua-Bar, L.; Pearlmutter, D.; Erell, E. The cooling efficiency of urban landscape strategies in a hot dry climate. Landsc. Urban Plan. 2009, 92, 179-186. [CrossRef]

23. Ward Thompson, C.; Roe, J.; Aspinall, P.; Mitchell, R.; Clow, A.; Miller, D. More green space is linked to less stress in deprived communities: Evidence from salivary cortisol patterns. Landsc. Urban Plan. 2012, 105, 221-229. [CrossRef]

24. Bolund, P.; Hunhammar, S. Ecosystem services in urban areas. Ecol. Econ. 1999, 29, 293-301. [CrossRef]

25. Mitsch, W.J.; Gossilink, J.G. The value of wetlands: Importance of scale and landscape setting. Ecol. Econ. 2000, 35, 25-33. [CrossRef]

26. Boyer, T.; Polasky, S. Valuing urban wetlands: A review of non-market valuation studies. Wetlands 2004, 24, 744-755. [CrossRef]

27. Rooney, R.C.; Foote, L.; Krogman, N.; Pattison, J.K.; Wilson, M.J.; Bayley, S.E. Replacing natural wetlands with stormwater management facilities: Biophysical and perceived social values. Water Res. 2015, 73, 17-28. [CrossRef]

28. Ravit, B.; Gallagher, F.; Doolittle, J.; Shaw, R.; Muñiz, E.; Alomar, R.; Hoefer, W.; Berg, J.; Doss, T. Urban wetlands: Restoration or designed rehabilitation? AIMS Environ. Sci. 2017, 4, 458-483. [CrossRef]

29. Gautam, M.; Acharya, K.; Shanahan, S.A. Ongoing restoration and management of las vegas wash: An evaluation of success criteria. Water Policy 2014, 16, 720-738. [CrossRef]

30. Faccioli, M.; Riera Font, A.; Torres Figuerola, C.M. Valuing the Recreational Benefits of Wetland Adaptation to Climate Change: A Trade-off Between Species' Abundance and Diversity. Environ. Manag. 2015, 55, 550-563. [CrossRef]

31. Wang, Y.; Bakker, F.; de Groot, R.; Wörtche, H. Effect of ecosystem services provided by urban green infrastructure on indoor environment: A literature review. Build. Environ. 2014, 77, 88-100. [CrossRef]

32. Wolch, J.R.; Byrne, J.; Newell, J.P. Urban green space, public health, and environmental justice: The challenge of making cities "just green enough". Landsc. Urban Plan. 2014, 125, 234-244. [CrossRef]

33. Björk, J.; Albin, M.; Grahn, P.; Jacobsson, H.; Ardö, J.; Wadbro, J.; Ostergren, P.O. Recreational values of the natural environment in relation to neighbourhood satisfaction, physical activity, obesity and wellbeing. $J$. Epidemiol. Community Health 2008, 62. [CrossRef] [PubMed]

34. Velarde, M.D.; Fry, G.; Tveit, M. Health effects of viewing landscapes - Landscape types in environmental psychology. Urban For. Urban Green. 2007, 6, 199-212. [CrossRef] 
35. Ma, B.; Zhou, T.; Lei, S.; Wen, Y.; Htun, T.T. Effects of urban green spaces on residents' well-being. Environ. Dev. Sustain. 2019, 21, 2793-2809. [CrossRef]

36. Shin, J.-H. Toward a theory of environmental satisfaction and human comfort: A process-oriented and contextually sensitive theoretical framework. J. Environ. Psychol. 2016, 45, 11-21. [CrossRef]

37. Krajter Ostoić, S.; Konijnendijk van den Bosch, C.C. Exploring global scientific discourses on urban forestry. Urban For. Urban Green. 2015, 14, 129-138. [CrossRef]

38. Krajter Ostoić, S.; Konijnendijk van den Bosch, C.C.; Vuletić, D.; Stevanov, M.; Živojinović, I.; Mutabdžija-Bećirović, S.; Lazarević, J.; Stojanova, B.; Blagojević, D.; Stojanovska, M.; et al. Citizens' perception of and satisfaction with urban forests and green space: Results from selected Southeast European cities. Urban For. Urban Green. 2017, 23, 93-103. [CrossRef]

39. Koufteros, X.; Babbar, S.; Kaighobadi, M. A paradigm for examining second-order factor models employing structural equation modeling. Int. J. Prod. Econ. 2009, 120, 633-652. [CrossRef]

40. Blake, D.E. Contextual effects on environmental attitudes and behavior. Environ. Behav. 2001, 33, 708-725. [CrossRef]

41. Kaiser, F.; Fuhrer, A.; Wolfing, S. Environmental Attitude and Ecological Behaviour Florian. Asia Pacific Forum Sci. Learn. Teach. 1999, 11, 1-19. [CrossRef]

42. Balram, S.; Dragićević, S. Attitudes toward urban green spaces: Integrating questionnaire survey and collaborative GIS techniques to improve attitude measurements. Landsc. Urban Plan. 2005, 71, 147-162. [CrossRef]

43. Knez, I.; Thorsson, S.; Eliasson, I.; Lindberg, F. Psychological mechanisms in outdoor place and weather assessment: Towards a conceptual model. Int. J. Biometeorol. 2009, 53, 101-111. [CrossRef] [PubMed]

44. Peng, Y.; Feng, T.; Timmermans, H. Expanded comfort assessment in outdoor urban public spaces using Box-Cox transformation. Landsc. Urban Plan. 2019, 190, 103594. [CrossRef]

45. Peng, Y.; Feng, T.; Timmermans, H. A path analysis of outdoor comfort in urban public spaces. Build. Environ. 2019, 148, 459-467. [CrossRef]

46. Vanos, J.K.; Warland, J.S.; Gillespie, T.J.; Kenny, N. Review of the physiology of human thermal comfort while exercising in urban landscapes and implications for bioclimatic design. Int. J. Biometeorol. 2010, 54, 319-334. [CrossRef]

47. Klemm, W.; Heusinkveld, B.G.; Lenzholzer, S.; van Hove, B. Street greenery and its physical and psychological impact on thermal comfort. Landsc. Urban Plan. 2015, 138, 87-98. [CrossRef]

48. Gill, S.E.; Handley, J.F.; Ennos, A.R.; Pauleit, S. Adapting cities for climate change: The role of the green infrastructure. Built Environ. 2007, 33, 115-133. [CrossRef]

49. World Bank. DataBank: Population Estimates and Projections; WorldBank: Washington, DC, USA, 2020.

50. Chen, D.; Chen, H.W. Using the Köppen classification to quantify climate variation and change: An example for 1901-2010. Environ. Dev. 2013, 6, 69-79. [CrossRef]

51. Du, X.; Huang, Z. Spatial and temporal effects of urban wetlands on housing prices: Evidence from Hangzhou, China. Land Use Policy 2018, 73, 290-298. [CrossRef]

52. Zhang, W.; Zhu, Y.; Jiang, J. Effect of the urbanization of wetlands on microclimate: A case study of XixiWetland, Hangzhou, China. Sustainability 2016, 8, 885. [CrossRef]

53. Song, S.; Christian, A.; Martin, P. Exploring integrated design guidelines for urban wetland parks in China. Urban For. Urban Green. 2020, 53, 126712. [CrossRef]

54. Hunan Prospecting Design and Research Institute. Master Plan (2017-2021) of National Yanghu Wetland Park in Changsha Hunan Province; Hunan Prospecting Design and Research Institute: Changsha, China, 2016. (In Chinese)

55. Hox, J.J.; Bechger, T.M. An introduction to structural equation modeling. Fam. Sci. Rev. 1999, 11, 354-373.

56. Duncan, O.D. Path Analysis: Sociological Examples. Am. J. Sociol. 1966, 72, 1-16. [CrossRef]

57. Tarka, P. An overview of structural equation modeling: Its beginnings, historical development, usefulness and controversies in the social sciences. Qual. Quant. 2018, 52, 313-354. [CrossRef] [PubMed]

58. Bollen, K.A. Latent Variables in Psychology and the Social Sciences. Annu. Rev. Psychol. 2002, 53, 605-634. [CrossRef]

59. Bentler, P.M. Comparative fit indexes in structural models. Psychol. Bull. 1990, 107, 238-246. [CrossRef] 
60. Hu, L.T.; Bentler, P.M. Cutoff criteria for fit indexes in covariance structure analysis: Conventional criteria versus new alternatives. Struct. Equ. Model. 1999, 6. [CrossRef]

61. The Per-Capita Disposable Income of Residents in Changsha (2018). Available online: http://hnzd.stats.gov. cn/dcsj/sjfb/cs/zxfb/201805/t20180516_142203.html. (accessed on 28 June 2020).

(C) 2020 by the authors. Licensee MDPI, Basel, Switzerland. This article is an open access article distributed under the terms and conditions of the Creative Commons Attribution (CC BY) license (http://creativecommons.org/licenses/by/4.0/). 